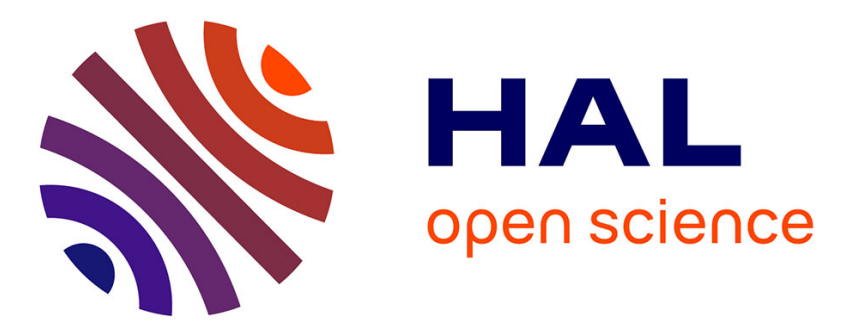

\title{
Remote acoustic monitoring of manganese nodules on the ocean bottom
}

\author{
A. Bunchuk, A. Ivakin
}

\section{To cite this version:}

A. Bunchuk, A. Ivakin. Remote acoustic monitoring of manganese nodules on the ocean bottom. Journal de Physique IV Proceedings, 1994, 04 (C5), pp.C5-1305-C5-1308. 10.1051/jp4:19945290 . jpa-00253003

\section{HAL Id: jpa-00253003 https://hal.science/jpa-00253003}

Submitted on 1 Jan 1994

HAL is a multi-disciplinary open access archive for the deposit and dissemination of scientific research documents, whether they are published or not. The documents may come from teaching and research institutions in France or abroad, or from public or private research centers.
L'archive ouverte pluridisciplinaire HAL, est destinée au dépôt et à la diffusion de documents scientifiques de niveau recherche, publiés ou non, émanant des établissements d'enseignement et de recherche français ou étrangers, des laboratoires publics ou privés. 


\title{
Remote acoustic monitoring of manganese nodules on the ocean bottom
}

\author{
A.V. BUNCHUK and A.N. IVAKIN \\ N.N. Andreev Acoustics Institute, 4 Shvernik Street, 117036 Moscow, Russia
}

\begin{abstract}
A wide set of experimental and theoretical investigations have been conducted to find out acoustic properties of the deep-sea bottom covered with manganese nodules. The field experiments have been carried out in four regions of the Pacific and Indian oceans at the frequency range $2-20 \mathrm{kHz}$ with the aim to detect acoustically the presence of bottom nodules and to estimate their parameters. The theoretical model of sound scattering and reflection by a set of nodules on the bottom has been developed, in which the explicit form of connection between characteristics of bottom reradiated acoustic signals and nodules parameters have been established. It made possible to explain all the obtained experimental data and to solve some inverse problems. The main results of the investigations are discussed and considered as the basis for acoustic monitoring of nodules deposits.
\end{abstract}

\section{INTRODUCTION}

Since 1983 at the Acoustics Institute, a wide set of experimental and theoretical investigations of acoustic properties of the deep-sea bottom covered with manganese nodules have been conducted. First, the possibility of remote acoustic detection and outlining of nodule deposits have been studied. Secondly, the possibility of remote acoustic monitoring and estimation of the nodules abundence and other parameters have been investigated.

A set of the field experiments have been conducted in four regions of the Pacific and Indian oceans at the frequency range 2-20 kHz, and a number of energy and correlation characteristics of bottom echo signals have been studied. The field experiments [1-3] have shown, that availability of manganeze nodules is displayed by increase of both the sound reflectivity and scattering strength and by appearance of their unusual, comparing nodules-free bottom, frequency-angular dependences.

A theoretical model of sound scattering and reflection by a set of nodules laid on the bottom has been developed [4], in which the explicit form of connection between characteristics of bottom reradiated acoustic signal and nodules parameters have been established. As a result, it made possible to explain all the obtained experimental data and to solve some inverse problems.

It has been recognized that the spatial distribution of amplitudes of signals reflected and scattered from the bottom (and of some other signals parameters) can be mapped and these maps appears to be the ones of the nodules abundance over the ocean bottom $[1-3,5]$.

In this paper, the mentioned experimental and theoretical results are discussed and considered as the basis for acoustic monitoring of nodules deposits. 


\section{EXPERIMENTAL RESULTS}

A number of field experiments in the Pacific and the Indian ocean [3] have shown, that over the frequency range of $4-20 \mathrm{kHz}$, the average amplitude of normally reflected signals is approximately linear with nodules packing coefficient $\varepsilon$ : $A \approx A_{0}+A_{1} \varepsilon, \quad 0<\varepsilon<0.8$, where $A_{0}$ is the average amplitude of signals reflected from nodules-free bottom. At frequencies below $4 \mathrm{kHz}$ A has only a weak (if any) dependence on $\varepsilon$. Later this dependence has been provided in the model laboratory experiments [6].

It has been shown also, that over the nodules covered bottom, normal reflection coefficient $V$ has a maximum at the frequency $f_{m}$, which varies with nodules mean radius $\bar{a}$ as $f_{m}(k H z) \approx 21, \bar{a}(\mathrm{~cm})$. In contrast to it the dependence of the nodulesfree bottom reflection coefficient $V_{0}$ slopes down monotonously with elevation of frequency (see Fig.1).



Figure 1. Experimental frequency dependences of the bottom reflection coefficient $V$ in the presence $(1,2)$ and in the absence (3) of nodules. Theoretical curves have been accounted according to Eqs. (2), (3) with $\bar{a}=2.0 \mathrm{~cm}, \bar{\varepsilon}=0.68$ (curve 1 ) and $\bar{a}=2.4 \mathrm{~cm}$, $\bar{\varepsilon}=0.6$ (curve 2 ).

Also, the lack of angular dependence of the nodules sound backscattering coefficient has been established at incident angles $20-75^{\circ}$.

The evidence of notable variabilities of nodules bottom local concentration and sizes have been indicated and corresponding spatial correlation scales of such variabilities have been determined. There have been also overcome difficulties of the field experiments performance connected with space navigation eriors in establishing the position of the vessel. At last it has been ascertained that the spatial distribution of bottom reflected tone and noise signals amplitudes (and of some other signals parameters) has temporal stability and can be mapped as natural geophysical parameters can be. These amplitudes distributions maps are in reality the maps of the assumed nodules abundance over the ocean bottom $[2,3,5]$. The same conclusion has been made about the maps of spatial distribution of the bottom backscattering signals intensities $[1]$. 


\section{THEORETICAL MODELLING}

The theoretical model has been developed to discribe sound scattering ard reflection from the nodules covered ocean bottom. [4]. For this model the calculations of energy and correlation characteristics of echo signals from the ocean bottom have been carried out and the results have been analyzed and compared with a wide set of obtained experimental data, indicating a good agreement between them.

In the most simple variant of this model, nodules are considered to be a set of identical spheres chaotically distributed on an acoustically transparent plane. For the nodules sound reflection and backscattering coefficients $v_{n}$ and $m_{n}$ it has been found [4]

$V_{n}=2\left[\left(\varepsilon \tan ^{2} \theta_{d}+\varepsilon^{2} / k^{2} a^{2}\right) F(k a)\right]^{1 / 2}, \quad m_{n}=(\varepsilon / \pi) F(k a)$

where $k$ is the wave number of sound in water, a is the radius of a nodule-sphere, $\theta_{d}$ is the half-width of a directivity pattern of a sound trasmitting-receiving system, $F(\mathrm{ka})$ is the backscattering cross-section of a nodule-sphere normalized on $\pi \mathrm{a}^{2}$. In line with the obtained experimental data, as it can be seen from (1), $m_{n}$ varies in proportion to $\varepsilon$ and does not depend on incident angle, $V_{n}$ increases with the increase of $\varepsilon$ and its frequency dependence has a maximum at ka $\approx 1$.

The second stage of the studies has been undertaken to solve the problem of remote exploration of those nodules deposits which were found and outlined during the first experimental stage of their remote detection. Nodules mean sizes and abundance should be determined in this stage by means of the solving of the inverse acoustic problem.

First of all the above variant of theoretical model has been refinded [4] by taking into consideration as nonuniform nodules location over both flat and statistically rough underlaid bottom surface so as nodules radii distribution. At the same time the conditions have been found out for the results independence both on the existence and the value of the bottom surface irregularities and on the directivity pattern of sonar. In terms of these modifications, from Eqs. (1) follows

$v_{n} \approx \bar{\varepsilon} F_{3}(\bar{k} \bar{a})$

where $\bar{\varepsilon}=\left\langle\varepsilon^{2}\right\rangle^{1 / 2}, \bar{a}=\langle a\rangle$, angle brackets signify the ensemble average, $F_{3}(x) \approx 1.8 \times \exp \left(-0.7 x^{2}\right)$. For not very large nodules $(\bar{a}<5-6 \mathrm{~cm}) \mathrm{Eq}$. (2) holds true: if signals friquency is below $15-20 \mathrm{kHz}$ and the sonar beam width $\theta_{\mathrm{d}}<10-20^{\circ}$. In practice the eqiations $(1,2)$ should be added by empiric relationship [7]

$\mathrm{V} \approx\left(\mathrm{v}_{\mathrm{n}}^{2}+\mathrm{v}_{0}^{2}\right)^{1 / 2}$

where $V$ is the actually measured nodules covered bottom reflection coefficient, $V_{0}$ is the nodules-free bottom reflection coefficient.

With the help of the renewed theoretical model, all spectral and correlation properties of the nodules reflected signals have been explained, as well as a number of angle and frequency dependences of nodules backscattering coefficient $m_{n}$ [4].

Besides, coupled with the above empirically determined requirement for signals frequency to be higher than $4-5 \mathrm{kHz}$, the Eqs. $(2,3)$ can be used for inverse acoustic problem solution.

\section{INVERSE PROBLEMS}

The above mentioned experimental and theoretical results may be considered as 
the basis for solving some inverse problems. Indeed, if reflection coefficient $v_{n}$ is measured at two frequencies, then $\bar{\varepsilon}$ and $\bar{a}$ can be estimated. An example of such estimation is presented at Fig. 1.

Note, that another important nodules parameter, their abundance $Q$, which is the total mass of nodules on the unit of bottom surface cross-section, can be estimated from equation $Q \approx(4 / 3) \bar{\varepsilon} p$, where $p$ is the nodules mass density.

The final stage of the investigations has included the field test of the algorithms which were developed for the inverse acoustic problem solution. Their validation for adequacy has been performed in the Pacific in 1991. As a result, the theory conclusions concerning the necessity for sonar beam width narrowing has been proved. Becides, the method has been worked out for experimental estimation of $v_{n}$ by measuring the reflection coefficient $V$, taking into account that $V$ automatically equals to $v_{0}$ for nodules-free bottom $\left(v_{n} \ll v_{0}\right)$. This method is valued without a priori information on nodules bottom location and with allowance made for experimental errors dV. It has been shown [8] that the inverse acoustic problem can not be solved until the inequality $V_{n}>d V$ satisfied. This inequality combined with

(2) imposes limitations on the range of possible nodules sizes and packing coefficients to be determined by the above mentioned algorithms.

Some illustration of the inverse acoustic problem solving by means of the two-frequency field remote measurements are given in the Table 1 . The measurements were performed from the ocean surface in the $5100 \mathrm{~m}$ deep Pasific at different pairs of the frequencies $5,10,15$ and $20 \mathrm{kHz}$.

Table 1. Nodules estimated and real parameters.

\begin{tabular}{|c|c|c|c|c|c|c|}
\hline Experi- & $!$ & $N \circ d u$ & $\mathrm{u} l \mathrm{l} s$ & & $\mathrm{aram} e t$ & $\mathrm{~s}$ \\
\hline $\begin{array}{l}\text { ment } \\
\text { number }\end{array}$ & $!$ & $\begin{array}{l}\text { Mean radius, } \\
\text { Estimation }\end{array}$ & $\begin{array}{l}\mathrm{cm} \\
\text { Real }\end{array}$ & $!$ & $\begin{array}{l}\text { Packing coe } \\
\text { Estimation }\end{array}$ & $\begin{array}{r}\text { icient } \\
\text { Real }\end{array}$ \\
\hline 1 & $!$ & 2.4 & $1.5-2.5$ & $!$ & 0.29 & 0.25 \\
\hline 2 & $!$ & 1.5 & $1.5-2.5$ & $!$ & 0.55 & 0.50 \\
\hline 3 & ! & 3.3 & $4-5$ & $!$ & 0.29 & 0.30 \\
\hline 4 & ! & 3.0 & $1-3$ & $!$ & 0.19 & 0.17 \\
\hline 5 & ! & 2.3 & 2.5 & $!$ & 0.52 & 0.50 \\
\hline
\end{tabular}

It is worth to remark that as follows from our practice, the most adequate hydroacoustic equipment for remote sensing of manganese nodules deposits are the chip sonar for the frequency range of $5-20 \mathrm{kHz}$ like that described in [9] and multyelement receiving array like the "Plast" antenna described in [10]. This equipment enables searching, monitoring and mapping of nodules deposites and their parameters in real time with permissible experimental errors.

\section{References.}

[1] Antokolskii L.M., Bunchuk A.V., Selivanovskii D.A. and Khalilullov Sh.Sh., Okeanologia 29 (1989) $748-754$.

[2] Bunchuk A.V., Sechkin V.A. and Khalilullov Sh.Sh., In: Acoustics in ocean (Nauka, Moscow, 1992) pp. 189-199.

[3] Bunchuk A.V. and Khalilullov Sh.Sh., Akusticheskii zhurnal 40 (1994) in press.

[4] Bunchuk A.V. and Ivakin A.N., Sov. Phys. Acoust., 35 (1989) 5-11.

[5] Ivakin A.N., Ilyin A.V. and Lysanov Yu.P., Okeanologia 33 (1993) 536-538.

[6] Gorskaya N.V., Gryaznova I.Yu., Gurbatov S.N. and Nikolaev G.N., Sov. Phys. Acoust. , 36 (1990) 228-231.

[7] Bunchuk A.V., Okeanologia 32 (1992) 228-233.

[8] Bunchuk A.V., Okeanologia 32 (1992) 466-473.

[9] Schock S.G. and Le Blanc L.R., Sea Technology N9 (1990) 35-43.

[10] Brekhovskikh L.M., Volovov V.I. and Lysanov Yu.P., Sov.Phys.Acoust., 35 (1989) 413-419. 